УДК 621.391

ТРИФОНОВ А. П., МИЛОГОРОДСКИЙ А. А.

\title{
ОЦЕНКА ДЛИТЕЛЬНОСТИ ПРЯМОУГОЛЬНОГО ОПТИЧЕСКОГО ИМПУЛЬСА ПРИ НЕИЗВЕСТНОЙ ИНТЕНСИВНОСТИ ФОНА *
}

\author{
Воронежский государственный университет, \\ Россия, Воронеж, 394006, Университетская пл., д. 1
}

\begin{abstract}
Аннотация. Выполнены синтез и анализ квазиправдоподобного и асимптотически максимально правдоподобного алгоритмов оценки длительности. Найдены потери в точности оценок вследствие априорного незнания интенсивности фона.
\end{abstract}

Ключевые слова: квазиправдоподобия оценка; асимптотическая оценка максимального правдоподобия; рассеяния оценок; априорная параметрическая неопределенность

Модель оптического импульса с прямоугольным профилем интенсивности используется во многих приложениях оптической связи и локации [1-7]. Рассмотрим оценку неизвестной длительности оптического импульса с прямоугольным профилем интенсивности при наличии пуассоновского фона. В [7] исследована оценка длительности оптического импульса с априори неизвестной интенсивностью, но при априори известной интенсивности фона. Здесь, в отличие от [7] полагается, что интенсивность импульса априори известна, но априори неизвестна интенсивность пуассоновского фона. Считаем, что на интервале времени $[0, T]$ наблюдается реализация пуассоновского процесса $\pi(t)$ с интенсивностью

$$
\lambda(t)=\beta s(t)+\alpha_{0},
$$

$$
s(t)= \begin{cases}1, & 0 \leq t \leq \tau_{0}, \\ 0, & t<0, t>\tau_{0},\end{cases}
$$

где $\alpha_{0}-$ неизвестная интенсивность фона, $\beta$ - априори известная интенсивность импуль$\mathrm{ca}, \tau_{0}$ - неизвестная длительность импульса, которая может принимать значения из интервала $\left[T_{1}, T_{2}\right]$, причем $0<T_{1}<T_{2}<T$. Если известна интенсивность фона $\alpha_{0}$, то для оценки длительности импульса $\tau_{0}$ возможно использовать метод максимального правдоподобия [8], согласно которому оценка длительности определяется как положение наибольшего максимума логарифма функционала отношения правдоподобия (ФОП).

Выражение для логарифма ФОП [9] имеет вид

$$
L_{0}(\tau)=\pi_{\tau} \ln \left(1+\beta / \alpha_{0}\right)-\beta \tau,
$$

* Исследование выполнено за счет гранта Российского научного фонда (проект № 15-11-10022). 


\section{БИБЛИОГРАФИЧЕСКИЙ СПИСОК}

1. Шереметьев А. Г. Статистическая теория лазерной связи / А. Г. Шереметьев. - М. : Связь, 1971. $-264 \mathrm{c}$.

2. Волохатюк B. A. Вопросы оптической локации / В. А. Волохатюк, В. М. Кочетков, Р. Р. Красовский - М. : Сов. радио, 1971. - 256 с.

3. Гальярди Р. М. Оптическая связь / Р. М. Гальярди, Ш. Карп. - М. : Связь, 1978. — 424 с. 
4. Воробьев В. И. Оценка координат источника оптического излучения с прямоугольным профилем интенсивности / В.И.Воробьев // Оптико-механическая промышленность. - 1978. - № 4. - С. 14-16.

5. Воробьев В. И. Оптическая локация для радиоинженеров / В. И. Воробьев. - М. : Радио и связь, 1983. - $176 \mathrm{c}$.

6. Овчинникова T. М. Обнаружение и оценка момента изменения неизвестной интенсивности пуассоновского потока. I / Т. М. Овчинникова, А. П. Трифонов // Автоматика и телемеханика. - 1999. - № 1. C. 66-76. - Режим доступа : http://mi.mathnet.ru/at24.

7. Трифонов А. П. Оценка длительности оптического импульса с прямоугольным профилем интенсивности неизвестной высоты / А. П. Трифонов, А. А. Милогородский // Известия вузов. Радиоэлектроника. - 2016. - T. 59, № 10. - C. 3-12. - DOI : $10.20535 / \mathrm{S} 0021347016100010$.

8. Куликов Е. И. Оценка параметров сигналов на фоне помех / Е. И. Куликов, А. П. Трифонов. - М. : Сов. радио, 1978. - 296 с.
9. Большаков И. А. Прикладная теория случайных потоков / И. А. Большаков, В. С. Ракошиц. - М. : Сов. радио, 1978 . - 248 с.

10. Мудров В. И. Методы обработки измерений. Квазиправдоподобные оценки / В. И. Мудров, В. Л. Кушко. - М. : Радио и связь, 1983. - 304 с.

11. Стратонович Р. Л. Избранные вопросы теории флюктуации в радиотехнике / Р. Л. Стратонович. - М. : Сов. радио, 1961. - 550 с.

12. Сосулин Ю. Г. Теория обнаружения и оценивания стохастических сигналов / Ю. Г. Сосулин. - М. : Сов. радио, 1978. - 320 с.

13. Трифонов А. П. Статистические свойства высоты и положения абсолютного максимума марковского случайного процесса типа Башелье / А. П. Трифонов, Ю. Э. Корчагин, М. Б. Беспалова // Вестник ВГУ. Серия: Физика. Математика. - 2014. — № 4. С. 35-43. - Режим доступа : http://www.vestnik.vsu.ru/program/view/view.asp?sec $=$ p hysmath\&year $=2014 \&$ num $=04 \& f$ name $=2014-04-07$. 